\title{
Unique Adsorption Properties of Cationic Dyes Malachite Green and Rhodamine-B on Longan (Dimocarpus longan) Peel
}

\author{
Risfidian Mohadi ${ }^{13 *}$, Normah ${ }^{3}$, Erni Salasia Fitri ${ }^{2}$, Neza Rahayu Palapa ${ }^{2}$ \\ ${ }^{1}$ Graduate School of Mathematics and Natural Sciences, Faculty of Mathematics and Natural Sciences, Sriwijaya University, Palembang, 30662, Indonesia \\ ${ }^{2}$ Research Center of Inorganic Materials and Coordination Complexes, Faculty of Mathematics and Natural Sciences, Sriwijaya University, Palembang, 30662, Indonesia \\ ${ }^{3}$ Magister Programme Graduate School of Mathematics and Natural Sciences, Sriwijaya University, Palembang, 30662, Indonesia \\ *Corresponding author: risfidian.mohadi@unsri.ac.id
}

\begin{abstract}
This research converts agricultural waste Longan (Dimocarpus longan) Peel is used in the adsorption process to reduce cationic dyes rhodamine- $B$ and malachite green contaminants from aqueous solution. Longan (Dimocarpus longan) Peel was characterized by FT-IR, analysis XRD, SEM, BET, and TG-DTA. The characterization results show that Longan (Dimocarpus longan) Peel contains cellulose compounds and has a specific surface area $17.175 \mathrm{~m}^{2} / \mathrm{g}$, with this Longan (Dimocarpus longan) Peel has the potential as a bio adsorbent. The adsorption capacity is proven by adsorption capacity $\left(Q_{m}\right)$ shows that the bioadsorbent adsorption of malachite green has a large adsorption capacity of $182.64 \mathrm{mg} / \mathrm{g}$, while the adsorption capacity of rhodamine-B $\left(\mathrm{Q}_{m}\right)$ reaches $52.557 \mathrm{mg} / \mathrm{g}$ and this bioadsorbent longan (Dimocarpus longan) peel is effective the adsorption was stable until the third cycle.
\end{abstract}

Keywords

Bioadsorbent, Longan, Malachite Green, Rhodamine-B, Adsorption

Received: 14 October 2021, Accepted: 24 January 2022

https://doi.org/10.26554/sti.2022.7.1.115-125

\section{INTRODUCTION}

Water is the most important resource and is needed by humans, living things, and plants. Water is essential for life on earth and accounts for up to $70.9 \%$ (Tariq et al., 2020). However, many industries are growing rapidly nowadays, so many industries directly dispose of their waste into the environment without treating it first (Karthikeyan and Meenakshi, 2020). Finally, it can pollute water which can affect human life, living things, and the environment. Globally, environmental pollution is an important problem, especially in developing countries. About 10,000 synthetic dyes are discharged into the environment directly (Fang et al., 2021). Among other waste pollutants, textile dye pollutants have become the main contaminants. This textile dye is very dangerous because it is carcinogenic (Ali et al., 2020), toxic (Ting et al., 2021), exhibits teratogenic effects, and can affect photosynthesis in water bodies. The dyes that are widely used in industry are malachite green and rhodamine $\mathrm{B}$, which are cationic dyes that are very soluble in water so they are considered dangerous and cause cancer (Cheng et al., 2018), respiratory disease kidney failure, and are ecotoxicologically threatening the environment (Kumari et al., 2020). Malachite green is a commonly used dye and its molecular structure is shown in Figure $1 \mathrm{a}$, while rhodium b its molecular structure is shown in Figure $1 \mathrm{~b}$.

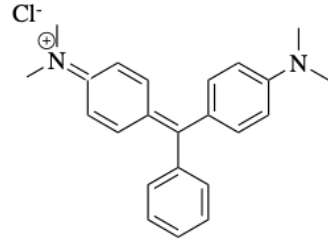

(A)

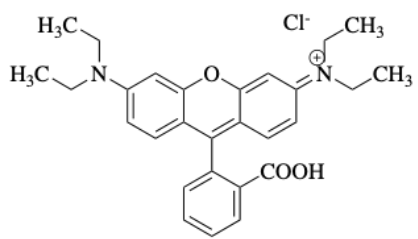

(B)
Figure 1. Chemical Structure of Malachite Green (a) and Rhodamine-B (b)

Therefore, the removal of dyes from textile waste is a major concern of researchers around the world. Conventional methods such as chemical coprecipitation (Mamat et al., 2018), flocculation, coagulation, precipitation, membrane filtration, degradation by microorganisms, and adsorption methods (Ahmed et al., 2020; Normah et al., 2021; Qu et al., 2019). Among all the methods, the adsorption process is found to be useful and common because it is cost-effective, easy to operate, and highly efficient (Fang et al., 2021). Recently, the application of bioadsorbents for pollutant adsorption has developed as an interesting research area. The high-performance adsorption 
materials mainly include activated carbon, nano metal oxide, graphene (Alam and Al Riyami, 2018), zeolite, pulp, and bioadsorbent (Ma et al., 2021). Bioadsorbents have been widely used because of their environmentally friendly materials, low operating costs, thermal stability, higher cation exchange capacity, easy regeneration, and larger surface area. In addition, utilizing low-cost materials, namely agricultural waste. Agricultural waste bioadsorbents that are often used include sawdust, rice husks, walnut shells, longan peel, rambutan peel, duku peel, amarindus indica fruit shells (Vasu, 2007), langsat (Lansium domesticum) shell (Kurniawati et al., 2021), corn cob (Ismail et al., 2018), Napier grass stem (Tongpoothorn et al., 2019) and langsat shell (Kurniawaty, 2019), orange peel, banana peel (Yonika, 2021), and lemon peel. The dye waste as an adsorbent will interact and enter bound to the pores of the adsorbent so that the waste after the adsorption process will reduce pollutant levels.

Ismail et al. (2018) reported that corn cobs activated with sulfuric acid had an adsorption capacity of up to $98 \%$ for malachite green adsorption. Tariq et al. (2020) reported rhodamine$\mathrm{B}$ can be degraded using the photo-Fenton process (homogeneous photocatalysis) was reached to be $86 \%$ at optimal $\mathrm{pH}=3$ and degraded to $98 \%$. Cellulose bioadsorbent made from Napier grass stalks to remove malachite green from this game. Napier grass stems showed that the maximum adsorption capacity reached $32.27 \mathrm{mg} / \mathrm{g}$ within 90 minutes. Based on the research of Kurniawati et al. (2021) the metals Cd(II) and Pb(II) which were adsorbed using longan seeds and peel produced optimal conditions used for $\mathrm{Cd}(\mathrm{pH} 5)$ and $\mathrm{Pb}(\mathrm{pH}$ 3). The results showed that the absorption of $\mathrm{Pb}$ metal ions for longan peel and longan seeds reached $42.14 \%$ and $57.07 \%$, and $\mathrm{Cd}$ metal ions for seeds and longan shells reach $68.11 \%$ and $64.77 \%$. The potential of langsat shell powder (Lansium domesticum) to adsorb rhodamine-B with an adsorption capacity of $12.3743 \mathrm{mg} / \mathrm{g}$ (Adella and Kurniawati, 2020).

Waste is longan peel can be used as an environmentally friendly adsorbent. Longan is a Sapindaceae plant shown in Figure 2, it has been commercially cultivated in many areas such as China, Taiwan, Vietnam, Thailand, especially Indonesia. This fruit has a sweet taste and has positive benefits for health. Longan peel contains active compounds such as phenolic acids, polysaccharides, and flavonoids so longan peel has the potential to be a low-cost heavy metal bioadsorbent (Rahmanian et al., 2018). The abundance of The active site of the main component of longan skin is what allows longan skin to have an excellent ability to remove pollutants from aqueous solutions (Wang et al., 2016b). Longan (Dimocarpus longan) peel contains gallic acid $\left(\mathrm{C}_{7} \mathrm{H}_{6} \mathrm{O}_{5}\right)$, flavone glycosides, and hydroxynamic with the main content of flavones in the form of quercetin and kaempferol (Albo et al., 2021). The compounds contained in it contain various functional groups that can interact directly with the adsorbate used, so longan peel is good to use as an adsorbent (Chen et al., 2017).

In this study, the peel of longan (Dimocarpus longan) was prepared into a bioadsorbent and used as an adsorbent of mala-

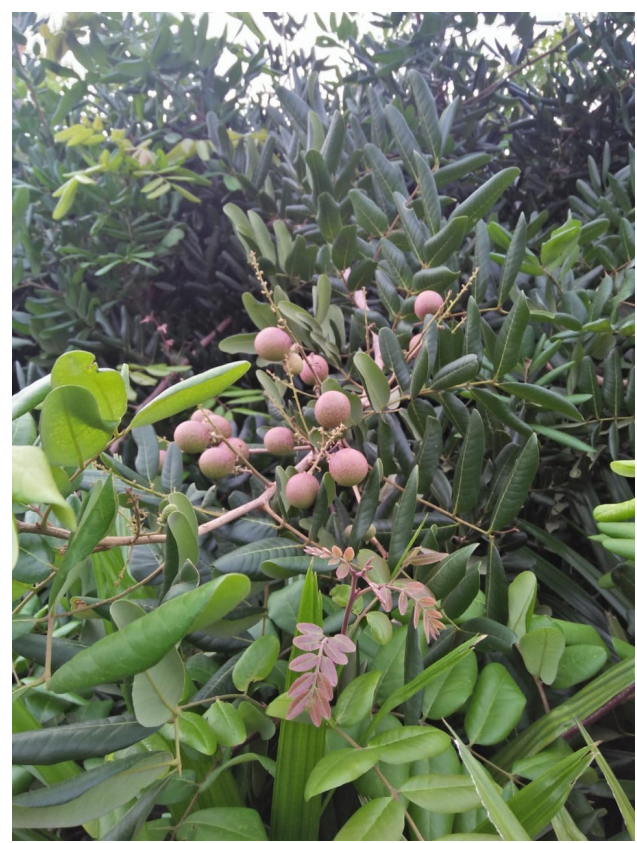

Figure 2. Indonesian Longan (Dimocarpus longan)

chite green and rhodamine-B from aqueous solutions. Factors affecting the effectiveness of adsorption were studied through the selectivity of the dye mixture, the effect of $\mathrm{pH}$, adsorption contact time, initial concentration, and adsorption temperature as well as the adsorbent regeneration process.

\section{EXPERIMENTAL SECTION}

\subsection{Chemicals and Instrumentations}

Chemicals such as hydrochloric acid, acetone, hydroxylamine chloride, ethanol, ethylene diamine tetraacetate (EDTA), sodium hydroxide, malachite green, rhodamine-B (Merck and Sigma Aldrich). Water was obtained from using Purite ${ }^{\circledR}$ ion exchange water purification process. The bioadsorbent of longan (Dimocarpus longan) was obtained from the local logan at Palembang, South Sumatera, Indonesia.

Characterization of bioadsorbent longan (Dimocarpus longan) was performed using FTIR Shimadzu Prestige-21 using $\mathrm{KBr}$ pellet and scanning sample at $400-4000 \mathrm{~cm}^{-1}$. Surface area analysis was performed using the BET Nova 400e Omnisorp apparatus. The sample was evacuated under liquid nitrogen before analysis. The morphology of bioadsorbent was measured using (SEM) SU 8000 series following analysis of the composition of bioadsorbent using EDX. Analysis of thermal was conducted using Thermogravimetry-Differential Thermal Analysis (TG-DTA) Shimadzu DTG-60H. The structure of bioadsorbent was analyzed using XRD Rigaku-6000. The concentration of dyes was analyzed using a Biobase BK-1800 PC spectrophotometer. Malachite green and rhodamine-B were analyzed at $617 \mathrm{~nm}$ and $554 \mathrm{~nm}$, respectively. 


\subsection{Preparation of Bioadsorbent and Characterization}

Bioadsorbent of longan (Dimocarpus longan) was prepared prior used for bioadsorbent of malachite green and rhodamine-B. Longan (Dimocarpus longan) shell was washed with ethanol and water, respectively for several times and dried at $110^{\circ} \mathrm{C}$ for several days. Longan (Dimocarpus longan) shell was grounded by mortar until passed through a $100 \mathrm{~mm}$ sieve. Characterization of longan (Dimocarpus longan) shell was performed by FTIR spectroscopy, surface area measurement, thermal analysis, morphology and composition analysis by SEM-EDX, and structure analysis by XRD.

\subsection{Adsorption Experiment}

Several factors of adsorption were investigated such as the effect of $\mathrm{pH}$, effect of adsorption time, effect of concentration of cationic dyes, and temperature. The desorption process and regeneration of bioadsorbent were also studied.

The effect of $\mathrm{pH}$ was studied through variation of $\mathrm{pH}$ of adsorption medium at 2-10 and the amount of adsorbed by analyzed. Adsorption time was studied by variation of adsorption time at 5-200 minutes with constant stirring on the batch adsorption system. Adsorption of malachite green and rhodamine-B using various initial concentrations and temperature was studied at $30,40,50$, and $60^{\circ} \mathrm{C}$ with a concentration of dyes was $50-85 \mathrm{mg} / \mathrm{L}$ for malachite green and $5-12 \mathrm{mg} / \mathrm{L}$ for rhodamine-B.

Desorption of dyes on bioadsorbent was performed using various reagents such as water, hot water, EDTA, hydroxylamine chloride, ether, ethanol, acetone, hydrochloric acid, and sodium hydroxide. The highest desorption reagent will be used for the regeneration process. Regeneration was conducted 3 times after adsorption of dyes using the same sample from the fresh, first, and second adsorption process.

\section{RESULTS AND DISCUSSION}

The FT-IR spectrum of longan (Dimocarpus longan) is shown in Figure 3. It can be seen that logan (Dimocarpus longan) appears a significant and wide peak at the wavenumber of $3433 \mathrm{~cm}^{-1}$ which corresponds to the $-\mathrm{OH}$ stretching vibration. According to Shaikhiev et al. (2022); Nor et al. (2015) the wave number at $2931 \mathrm{~cm}^{-1}$ can be associated with $\mathrm{C}-\mathrm{H}$ vibrations in both the $-\mathrm{CH}_{2}$ and $-\mathrm{CH}_{3}$ functional groups (Wang et al., 2016a; Zhang et al., 2016). The wavenumbers $2387 \mathrm{~cm}^{-1}$ characteristic peaks of $\mathrm{C}=\mathrm{C}$ and $1627 \mathrm{~cm}^{-1}$ can be attributed to the vibrations of the $\mathrm{C}=\mathrm{O}$ group of the aromatic ring. In addition, the wavenumber at $1230 \mathrm{~cm}^{-1}$ can be associated with $\mathrm{C}-\mathrm{C}$. with $\mathrm{C}-\mathrm{O}$ stretching, and $1056 \mathrm{~cm}^{-1}$ have a peak associated with the vibration of the $\mathrm{C}-\mathrm{O}$ group. Vibrations that appear in the FT-IR spectrum of longan (Dimocarpus longan) indicate that logan i contains cellulose, hemicellulose, and lignin (Ikhtiari et al., 2015; Kaykhaii et al., 2018).

The bioadsorbent longan (Dimocarpus longan) was analyzed using the nitrogen adsorption-desorption analysis shown in Figure 4. Figure 4 shows that the isotherm pattern in Figure 4 shows that the material follows the type IV, isotherm model.

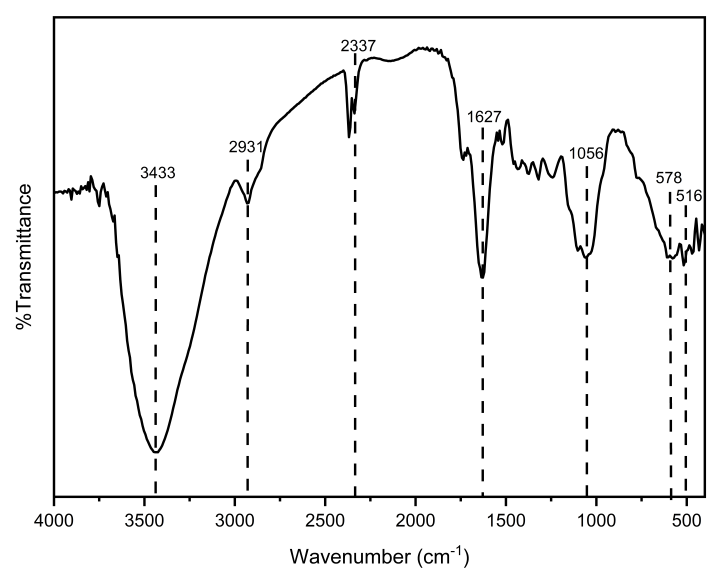

Figure 3. FTIR Spectrum of Logan (Dimocarpus longan)

Type IV isotherm indicates that the formation of multilayer and hysteresis phenomenon occurs (Brame and Griggs, 2016). Hysteresis is a material that has non-uniform pores so that adsorption-desorption does not overlap and there is a difference between nitrogen adsorption and desorption. According to Moller and Pich (2017), the type IV isotherm shows hysteresis with mesopore material with a size of 2-50 nm. Hysteresis on bioadsorbent longan (Dimocarpus longan) belongs to type $\mathrm{H} 2$. In type $\mathrm{H} 2$, this wide loop has a heterogeneous pore structure with sizes ranging from 2-6 nm and more than $10 \mathrm{~nm}$ in size. Thus, adsorption-desorption differences occur because they have heterogeneous sizes due to the blockage of smaller pores with a pore shape like a pile of paper with looser gaps (Grabi et al., 2021).

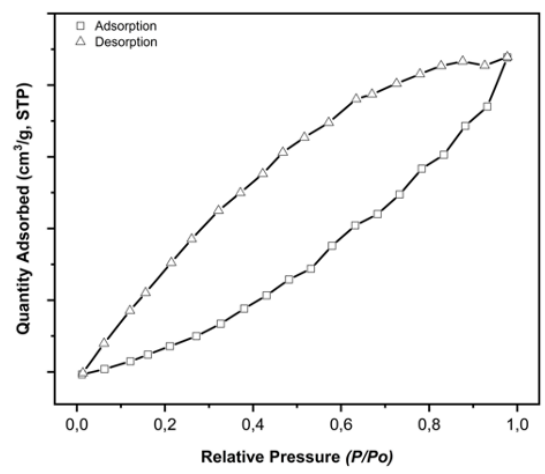

Figure 4. $\mathrm{N}_{2}$ Isotherm Adsorption-Desorption of Longan (Dimocarpus longan)

The BET analysis data are presented in Table 1. Table 1 shows that the surface area of Bioadsorbent longan (Dimocarpus longan) is $17.175 \mathrm{~m}^{2} / \mathrm{g}$ with a pore volume of $0.02 \mathrm{~cm}^{3} / \mathrm{g}$ and a pore diameter of $12.33 \mathrm{~nm}$. At lower temperatures, the bioadsorbent exhibits a relatively small surface area, due to insufficient carbonization. This indicates that the obtained carbon- 
containing almost no finite pore framework. The temperature of the bioadsorbent preparation greatly affects the number of pores because the cracking process can control the number of pores due to the cracking of the carbon basalt structural sheet from the carbon particle basalt structural sheet (Kalak et al., 2021).

Table 1. BET Analysis of Logan (Dimocarpus longan)

\begin{tabular}{cccc}
\hline Bioadsorbent & $\begin{array}{c}\text { Surface area } \\
\left(\mathrm{m}^{2} / \mathrm{g}\right)\end{array}$ & $\begin{array}{c}\text { Pore volume } \\
\left(\mathrm{cm}^{3} / \mathrm{g}\right)\end{array}$ & $\begin{array}{c}\text { Pore diameter } \\
(\mathrm{nm})\end{array}$ \\
\hline Longan & 17.175 & 0.02 & 12.33 \\
\hline
\end{tabular}

Analysis of TG-DTA longan (Dimocarpus longan) from Figure 5 . The differential thermal analyzer (DTA) method can be seen in black graphs to detect any thermal changes associated with exothermic or endothermic chemical events or reactions. This event can be seen in the form of a differential thermogram as maximum and minimum peaks. The maximum peak indicates an exothermic event where heat will be released by the sample. Figure 5 shows the results of the analysis of longan ( $D i$ mocarpus longan) with the appearance of an endothermic peak indicating a water loss of $100^{\circ} \mathrm{C}$. The exothermic peak between $320^{\circ} \mathrm{C}$ and $500^{\circ} \mathrm{C}$ appears to be related to the decomposition of functional groups with lower stability of longan material (Dimocarpus longan) where the decomposition of cellulose and lignin occurs.

Table 2. Comparison of Surface Area Properties of Several Bioadsorbent

\begin{tabular}{ccc}
\hline Bioadsorbent & $\begin{array}{c}\text { Surface Area } \\
\left(\mathrm{m}^{2} / \mathrm{g}\right)\end{array}$ & References \\
\hline Aphanothece sp. & 0.571 & (Satya et al., 2020) \\
Aloe Vera powder & 13.8 & (Moosa et al., 2016) \\
Sugarcane Bagasse & 0.991 & (Priyanto et al., 2021) \\
Banana peel & 0.32 & (Kusrini et al. , 2019) \\
Pineapple peel & 1.99 & (Pathak et al., 2015) \\
Orange Peel & 2.14 & (Pathak et al., 2015) \\
Longan & 17.175 & This Research \\
(Dimocarpus longan) & & \\
\hline
\end{tabular}

It can be seen that Table 2 shows that Longan (Dimocarpus longan) has a larger surface area compared to other bioadsorbents, this strongly supports the potential and ability of Longan (Dimocarpus longan) as an adsorbent to remove dyes and metals in waste.

Figure 6 shows the results of SEM analysis with the surface morphology of the longan peel (Dimocarpus longan) at a magnification of $100 \mathrm{~m}$. In Figure 6(a) it can be seen that the cavities found on the surface of the bioadsorbent peel of the longan (Dimocarpus longan) fruit with morphology form aggregates of non-uniform size on the surface. The composition of the bioadsorbent longan (Dimocarpus longan) can be seen in Figure 6(b). Based on Figure 6(b) above, shows that the highest percentage of composition mass is carbon. According to Chang and Li (2019) longan (Dimocarpus longan) can bind to adsorbate due to the presence of active groups in the form of hydroxide

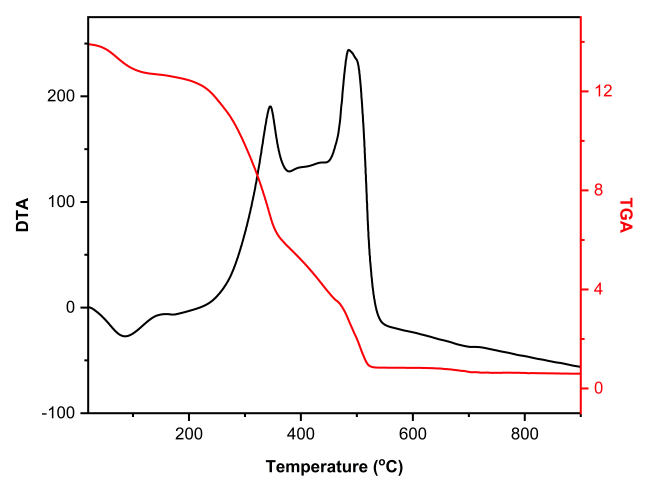

Figure 5. TG-DTA Profile of Longan (Dimocarpus longan)

(-OH), amine (-NH) aldehyde (-COH), and carboxyl (-COO) which can interact with the adsorbate and according to Lestari (2019) results from FTIR of longan (Dimocarpus longan) peel according to the composition of the SEM results.

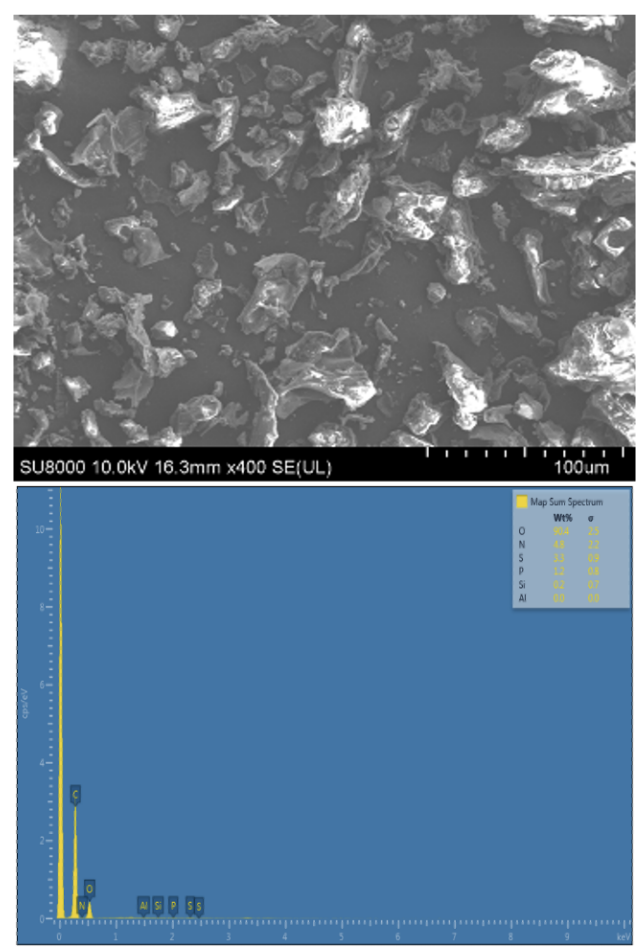

Figure 6. Surface Morphology and Composition of Longan (Dimocarpus longan)

Figure 7 shows the X-ray diffractogram pattern for the bioadsorbent longan (Dimocarpus longan). Figure 7 shows a wide peak with a diffraction angle of $23.05^{\circ}$ with a diffraction plane (002) indicating that the longan bioadsorbent (Dimocarpus longan) has low crystallinity, indicating the characteristics of amorphous cellulose compounds due to the influence of lignin and hemicellulose (Oliveira et al., 2016). Characterization with X-Ray Diffraction (XRD) can be used as supporting data to determine the diffraction angle of the bioadsorbent from 
longan (Dimocarpus longan).

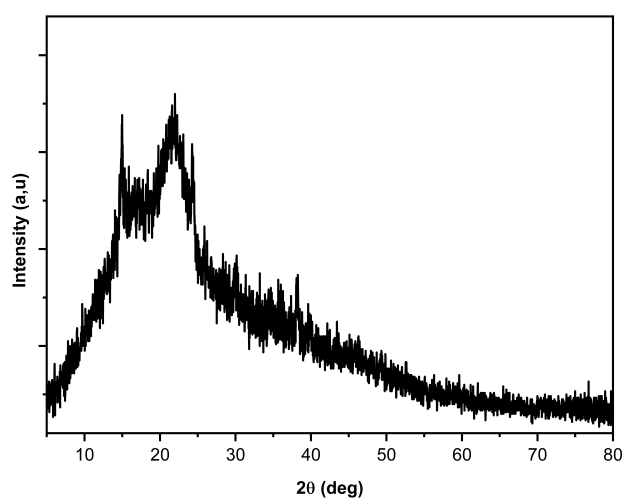

Figure 7. XRD Pattern of Logan (Dimocarpus longan)

The adsorption selectivity was carried out by mixing two dyes, namely malachite green (MG) and rhodamine-B (Rh-B), with a concentration of $8 \mathrm{mg} / \mathrm{L}$ and added bioadsorbent and the maximum wavelength of the mixture was measured using a UV-Vis spectrophotometer from 540 to 700 . The results of these measurements are presented in Figure 8. The adsorption selectivity of the mixed dyes was analyzed from changes in the concentration of the adsorbed which were increasing during the adsorption process from $0,15,30,60$ to 90 minutes and carried out at variations of $\mathrm{pH} 4,7$, and 9 . Figure 8 shows the results of adsorption selectivity at $\mathrm{pH} 4$ on MG dye with an initial concentration of $8.31 \mathrm{mg} / \mathrm{g}$ rambutan peel became $4.11 \mathrm{mg} / \mathrm{g}$, initial concentration of Rh-B dye $9.19 \mathrm{mg} / \mathrm{g}$ became 2.56 $\mathrm{mg} / \mathrm{g}$. The condition of $\mathrm{pH} 7$ in the initial concentration of MG dye was $10.96 \mathrm{mg} / \mathrm{g}$ to $6.37 \mathrm{mg} / \mathrm{g}$, the initial concentration of Rh-B dye was $10.42 \mathrm{mg} / \mathrm{g}$ to $3.21 \mathrm{mg} / \mathrm{g}$. The condition of $\mathrm{pH} 9$ on the initial concentration of MG dye was $9.16 \mathrm{mg} / \mathrm{g}$ to $3.37 \mathrm{mg} / \mathrm{g}$, the initial concentration of Rh-B dye was 10.12 $\mathrm{mg} / \mathrm{g}$ to $5.1 \mathrm{mg} / \mathrm{g}$. A drastic decrease occurred at minute 120 with different $\mathrm{pH}$ conditions. It can be concluded that the selective dye for bioadsorbent is $\mathrm{MG}$ dye at alkaline $\mathrm{pH}$ $(\mathrm{pH}=9)$. After knowing the most selective dye, then proceed with the regeneration adsorption process isotherm adsorption and thermodynamic adsorption.

Measurement of the optimum $\mathrm{pH}$ for adsorption of malachite green dye to longan (Dimocarpus longan) bioadsorbent was carried out using variations of $\mathrm{pH} 2,3,4,5,6,7,8,9,10$, and 11 with malachite green and rhodamine-B. The malachite green solution which has been adjusted to $\mathrm{pH}$ is then shaken for 120 minutes then its absorbance is measured using a UVVis spectrophotometer. The optimum $\mathrm{pH}$ of malachite green against longan (Dimocarpus longan) bioadsorbent can be seen in Figure 9(a) and the optimum $\mathrm{pH}$ for rhodamine- $\mathrm{B}$ is shown in Figure 9(b).

Based on Figure 9, obtained the optimum $\mathrm{pH}$ of malachite green dye is found at $\mathrm{pH} 6$ and rhodamine- $\mathrm{B}$ is found at $\mathrm{pH} 4$. $\mathrm{pH}$ has a direct influence on the mechanism of dye adsorption by the adsorbent. Figure 9(a) shows that there is an increase
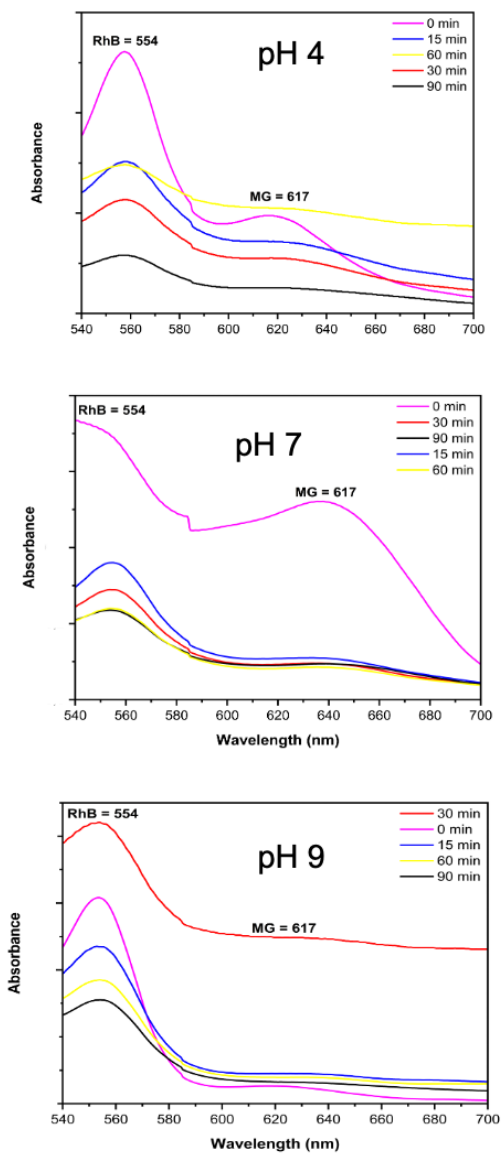

Figure 8. UV-Vis Spectrum of Dyes Mixtures After Adsorption at Several Times

in the adsorbed concentration with an increase in $\mathrm{pH}$ of 2-6 and the maximum is in the range of $\mathrm{pH} 6$. However, there is a decrease in the adsorbed concentration when the $\mathrm{pH}$ reaches an alkaline pH. Moghadam et al. (2013) reported that when at acidic $\mathrm{pH}$ the surface of the adsorbent will experience protonation and act as a positive charge, but at alkaline $\mathrm{pH}$, hydroxide ions $\left(\mathrm{OH}^{-}\right)$will cause the exchange of $\mathrm{Na}^{+}$ions from the $\mathrm{NaOH}$ solution so that the active site on the adsorbent cannot interact with the adsorbent. dyes so that at alkaline $\mathrm{pH}$ the number of ions adsorbed decreases.

The effect of variations in the time of bioadsorbent longan (Dimocarpus longan) on malachite green and rhodamine-B can be seen in Figure 10. Figure 10 shows that for dyes the adsorption equilibrium time reaches 100 minutes. The data obtained were calculated using pseudo-first-order (PFO) and pseudosecond-order (PSO) kinetic model equations according to the literature (Juleanti et al., 2021). Adsorption kinetics data on variations in adsorption contact time are shown in Table 3.

Based on the kinetic data in Table 3 shows that the linear regression value $\left(\mathrm{R}^{2}\right)$ in the calculation of the pseudo-first-order kinetic model (PFO) tends to be closer to the value 1 compared 
Table 3. Kinetic Model for Adsorption of Malachite Green and Rhodamine-B on Longan (Dimocarpus longan)

\begin{tabular}{ccccccccc}
\hline \multirow{2}{*}{ Dyes } & $\begin{array}{c}\text { Initial Concentration } \\
(\mathrm{mg} / \mathrm{L})\end{array}$ & $\mathrm{Qe}_{\text {exp }}$ & \multicolumn{3}{c}{$\mathrm{PFO}$} & \multicolumn{4}{c}{ PSO } \\
\cline { 4 - 9 } & & $(\mathrm{mg} / \mathrm{g})$ & $\begin{array}{c}\mathrm{Qe}_{\text {Calc }} \\
(\mathrm{mg} / \mathrm{g})\end{array}$ & $\mathrm{R} 2$ & $\mathrm{k}_{1}$ & $\begin{array}{c}\mathrm{Qe}_{\text {Calc }} \\
(\mathrm{mg} / \mathrm{g})\end{array}$ & $\mathrm{R}^{2}$ & $\mathrm{k}_{2}$ \\
\hline \multirow{2}{*}{$\mathrm{MG}$} & 25 & 4.857 & 4.843 & 0.997 & 0.023 & 7.138 & 0.737 & 0.001 \\
& 50 & 6.536 & 9.480 & 0.785 & 0.035 & 0.514 & 0.866 & 3.415 \\
& 55 & 8.679 & 9.554 & 0.805 & 0.035 & 9.416 & 0.998 & 0.006 \\
$\mathrm{Rh}-\mathrm{B}$ & 65 & 11.893 & 13.210 & 0.775 & 11.489 & 0.059 & 0.235 & 4.509 \\
& 4 & 1.178 & 1.049 & 0.931 & 0.035 & 1.284 & 0.997 & 0.051 \\
& 5 & 1.465 & 1.697 & 0.850 & 0.035 & 1.637 & 0.988 & 0.029 \\
& 6 & 1.835 & 9.016 & 0.928 & 28.949 & 32.581 & 0.743 & 9.458 \\
& 7 & 2.170 & 1.566 & 0.939 & 0.024 & 33.333 & 0.471 & 9.988 \\
\hline
\end{tabular}
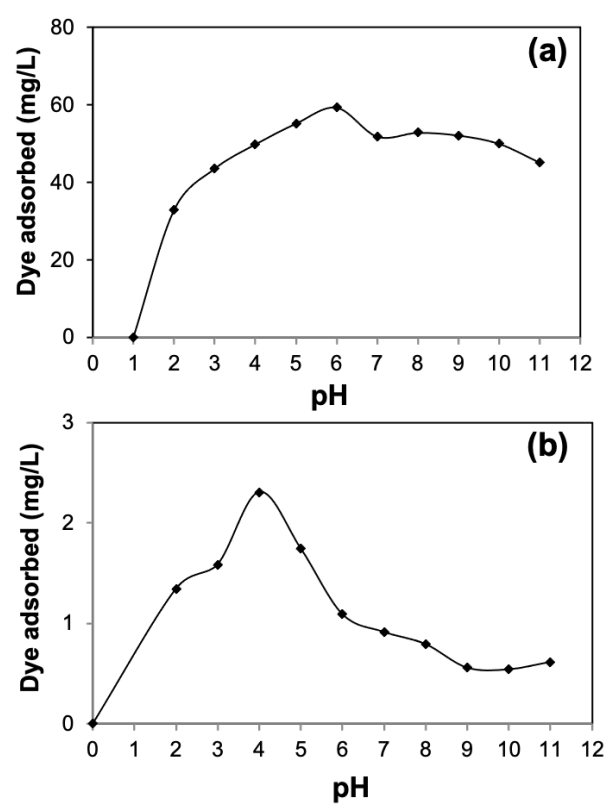

Figure 9. Effect of Various pH Adsorption of Malachite Green And Rhodamine-B on Longan (Dimocarpus longan)

to the pseudo-first-order (PFO) kinetic model, it can be concluded that the adsorption of malachite green and rhodamine$\mathrm{B}$ tends to follow the pseudo-first-order (PFO) equation for the bioadsorbent. Table 3 shows that the adsorbed concentration at equilibrium (experimental test) is directly proportional to the concentration used. According to Onder et al. (2020) the pseudo-first order (PFO) kinetic model indicates that adsorption tends to occur by physisorption with the adsorption equilibrium rate affecting only the adsorbent or adsorbate.

Figure 11 shows that as the adsorption temperature increases, it will cause an increase in the adsorbate adsorbed for each dye. The higher the concentration used, the more the adsorbed malachite green and rhodamine-B dyes will increase. Data on the effect of concentration and temperature on adsorption using bioadsorbents will then be used to determine the
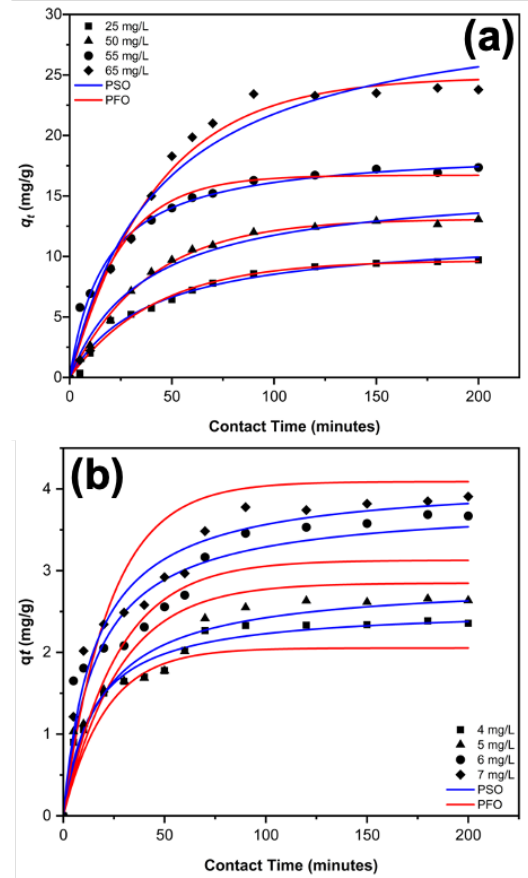

Figure 10. Effect of Adsorption Time Malachite Green (a); Rhodamin-B (b)

adsorption isotherm model using the Langmuir and Freundlich equation according to the literature (Wijaya et al., 2021). Langmuir and Freundlich's isotherm calculation of the data is shown in Table 4.

According to Zubair et al. (2018) Freundlich isotherm model assumes that the adsorbent surface is heterogeneous and supports multilayer adsorption and an adsorption process that occurs by physical (Wijaya et al., 2021), while the Langmuir isotherm assumes that adsorption occurs by the formation of a monolayer on the adsorbent surface that does not have interactions between adsorbate molecules (Mishra et al., 2020). The data in Table 4 shows that the Langmuir adsorption isotherm equation model has a linear regression 

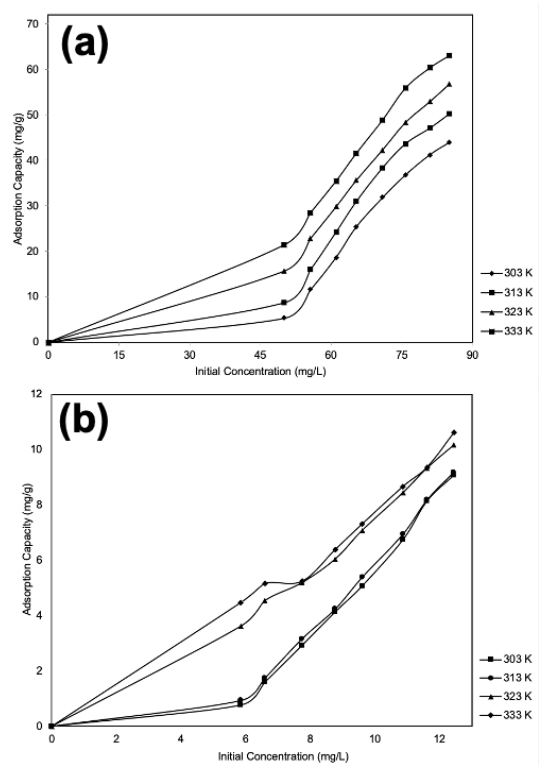

Figure 11. Thermodynamic Parameter Adsorption Malachite Green (a); Rhodamin-B (b) on Longan (Dimocarpus longan)

Table 4. Isotherm Parameter Adsorption of Malachite Green and Rhodamine-B on Longan (Dimocarpus longan)

\begin{tabular}{cccccccc}
\hline & Temp. & \multicolumn{5}{c}{ Model Isotherm Adsorption } \\
\cline { 3 - 8 } Dyes & $(\mathrm{K})$ & \multicolumn{3}{c}{ Langmuir } & \multicolumn{3}{c}{ Freundlich } \\
& & $\mathrm{Q}_{m}$ & $\mathrm{~K}_{L}$ & $\mathrm{R}^{2}$ & $\mathrm{n}$ & $\mathrm{K}_{F}$ & $\mathrm{R}^{2}$ \\
\hline MG & 30 & 1.829 & 0.027 & 0.964 & 0.114 & 1.428 & 0.984 \\
& 40 & 111.1 & 0.014 & 0.928 & 1.571 & 3.725 & 0.909 \\
& 50 & 158 & 0.02 & 0.93 & 1.749 & 5.336 & 0.949 \\
& 60 & 182.6 & 0.036 & 0.926 & 2.204 & 9.091 & 0.93 \\
Rh-B & 30 & 0.686 & 0.286 & 0.861 & 0.138 & 2295 & 0.859 \\
& 40 & 0.656 & 0.293 & 0.77 & 0.211 & 3254 & 0.813 \\
& 50 & 38.03 & 0.08 & 0.832 & 1.515 & 3.637 & 0.931 \\
& 60 & 52.56 & 0.137 & 0.863 & 1.139 & 4.017 & 0.89 \\
\hline
\end{tabular}

value $\left(\mathrm{R}^{2}\right)$ which tends to be closer to the value 1 than the Freundlich adsorption isotherm equation for malachite green and rhodamine-B. Based on Table 4 the value of adsorption capacity $\left(Q_{m}\right)$ shows that the bioadsorbent adsorption of malachite green has a large adsorption capacity of $182.64 \mathrm{mg} / \mathrm{g}$, while rhodamine-B reaches $52.557 \mathrm{mg} / \mathrm{g}$.

Furthermore, the thermodynamic parameters provide data on the $(\Delta \mathrm{G}),(\Delta \mathrm{H})$, and $(\Delta \mathrm{S})$ which are calculated according to the literature (Biesinger et al., 2011). The adsorption thermodynamic data are shown in Table 5 .

Table 5 shows the results of the calculation of negative adsorption values for $\Delta \mathrm{G}$ on each adsorbent. $\Delta \mathrm{G}$ its value increased with increasing adsorption temperature reaching a $\Delta \mathrm{G}$ value ranging from -0.190 - to $-1.923 \mathrm{~kJ} / \mathrm{mol}$. A negative value for $\Delta \mathrm{G}$ indicates that the $\mathrm{MB}$ adsorption process takes place spontaneously (Lesbani et al., 2021) and the adsorption used in the adsorption process is better at high temperatures. The $\Delta \mathrm{H}$ value showed a range of $27.495 \mathrm{~kJ} / \mathrm{mol}(\mathrm{MG})$ and 23.066 $\mathrm{kJ} / \mathrm{mol}$ (Rh-B) which was related to the tendency of malachite and rhodamine-B adsorption to occur by physical adsorption and a positive $\Delta \mathrm{H}$ value indicated that $\mathrm{MB}$ adsorption was endothermic (Biesinger et al., 2011). The value of $\Delta \mathrm{S}$ is positive, this is related to the irregularity of the particles during the adsorption process which increases due to the interaction between solid in the form of adsorbent-liquid in the form of malachite green and rhodamine-B adsorbate (Dang et al., 2020; Neolaka et al., 2020) .
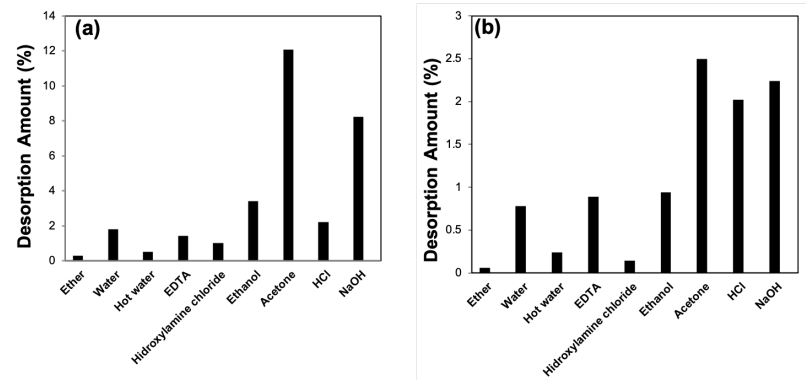

Figure 12. Desorption Process of Malachite Green (a) and rhodamine-B (b)

It can be seen in Figure 12 that the most suitable solvent for desorption of malachite green and rhodamine-B dyes using a bioadsorbent is acetone. Acetone solvent was able to release $12.08 \%$ malachite green and $2.5 \%$ rhodamine-B in the desorption process compared to other solvents. This shows that the interaction like dissolves like indicates and occurs between the dye adsorbate and the bioadsorbent from longan (Dimocarpus longan).
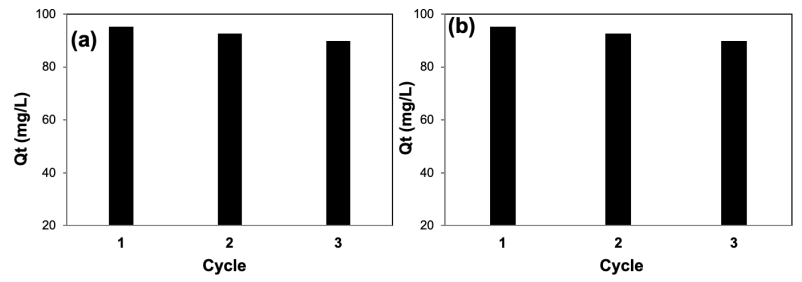

Figure 13. Cycling Bioadsorbent After Adsorption of Malachite Green (a) and Rhodamine-B (b)

Figure 13 shows the adsorption ability with repeated use. bioasorbent has adsorption capacity for the malachite green of $96.05 \%$ in the first cycle, its ability also decreased to $89.42 \%$ in the second cycle and the third cycle to $87.26 \%$. The result of regeneration of rhodamine-B adsorption in the first cycle was $95.25 \%$, the second cycle decreased to $10.13 \%$. Zn/Al-Hc reached the first cycle of $94.13 \%$, the second cycle of $90.54 \%$, the third cycle of $89.73 \%$, the fourth cycle of $84.21 \%$, the fifth cycle of $80.12 \%$, the sixth cycle of $78.33 \%$, and the last is $78.11 \%$. Bioadsorbent on longan (Dimocarpus longan) experienced an insignificant decrease. Based on these data, the bioadsorbent longan (Dimocarpus longan) has adsorption capacity with a regeneration cycle of up to a third. 
Table 5. Thermodynamic Parameter Adsorption of Malachite Green and Rhodamine-B on Longan (Dimocarpus longan)

\begin{tabular}{|c|c|c|c|c|c|c|}
\hline Dye & Concentration & $\mathrm{T}(\mathrm{K})$ & $\mathrm{Q}_{e}(\mathrm{mg} / \mathrm{g})$ & $\Delta \mathrm{H}(\mathrm{kJ} / \mathrm{mol})$ & $\Delta \mathrm{S}(\mathrm{J} / \mathrm{mol} . \mathrm{K})$ & $\Delta \mathrm{G}(\mathrm{kJ} / \mathrm{mol})$ \\
\hline \multirow{4}{*}{ MG } & \multirow{4}{*}{$85 \mathrm{mg} / \mathrm{L}$} & 303 & 44.000 & \multirow{4}{*}{27.495} & \multirow{4}{*}{0.091} & -0.190 \\
\hline & & 313 & 50.286 & & & -0.768 \\
\hline & & 323 & 56.721 & & & -1.345 \\
\hline & & 333 & 63.079 & & & -1.923 \\
\hline \multirow{4}{*}{ Rh-B } & \multirow{4}{*}{$12 \mathrm{mg} / \mathrm{L}$} & 303 & 9.083 & \multirow{4}{*}{23.066} & \multirow{4}{*}{0.084} & -0.090 \\
\hline & & 313 & 9.186 & & & -1.181 \\
\hline & & 323 & 10.172 & & & -2.273 \\
\hline & & 333 & 10.619 & & & -3.365 \\
\hline
\end{tabular}

The FT-IR spectrum in Figure 14 shows longan (Dimocarpus longan) before being adsorbed and after being adsorbed with the adsorbate. Figure 14 shows that there is a wavelength shift that is carried out by adsorption which will detect the functional group of the compound. the dye adsorption process is influenced by the number of functional groups, types of functional groups, interaction processes, adsorbent chemistry (Grabi et al., 2021). The results of the FT-IR spectrum can be seen in Figure 14 showing the appearance of a peak at the wavenumber of $2854 \mathrm{~cm}^{-1}$ because it has been in contact with the adsorbate. After treatment, strain vibrations of the $\mathrm{S}-\mathrm{O}$ and $\mathrm{S}=\mathrm{O}$ dye groups were observed at $1056 \mathrm{~cm}^{-1}$ and $1249 \mathrm{~cm}^{-1}$. In addition, the bands at $1372 \mathrm{~cm}^{-1}$ and $1342 \mathrm{~cm}^{-1}$ came from the vibrations of amine groups from dye molecules. Thus, the FT-IR spectrum shows the displacement of certain functional groups and the appearance of functional groups from the dye on the surface of the bioadsorbent. The shift of peaks shows the interaction between rhodamine-B and malachite green dye ions with the surface of the bioadsorbent. The interaction can not only be seen in the shift of peaks but also seen from the intensity of each peak (Krishni et al., 2014).

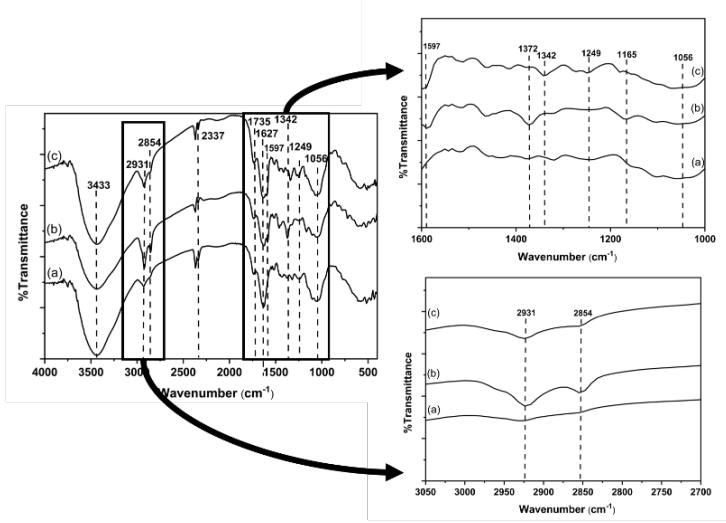

Figure 14. Spectrum FT-IR Before Adsorption (a), After Adsorption Malachite Green (b), After Adsorption Rhodamine-B (c) on Longan (Dimocarpus longan)

\section{CONCLUSIONS}

This study investigated waste longan (Dimocarpus longan) which was developed as a bioadsorbent to remove cationic dyes from aqueous solutions. adsorption capacity $\left(Q_{m}\right)$ shows that the bioadsorbent adsorption of malachite green has a large adsorption capacity of $182.64 \mathrm{mg} / \mathrm{g}$, while the adsorption capacity of rhodamine-B $\left(Q_{m}\right)$ reaches $52.557 \mathrm{mg} / \mathrm{g}$ and this bioadsorbent longan (Dimocarpus longan) peel is effective the adsorption was stable until the third cycle.

\section{ACKNOWLEDGEMENT}

The author thanks the Research Center of Inorganic Materials and Complexes FMIPA Sriwijaya University for support of this research and also for analysis and instrumentation.

\section{REFERENCES}

Adella, F., and D. Kurniawati (2020). Adsorption of Rhodamine B from Aqueous Solution Using Langsat (Lansium domesticum) Shell Powder. In International Conference on Biology, Sciences and Education (ICoBioSE 2019). Atlantis Press, $273-276$

Ahmed, D. N., L. A. Naji, A. A. Faisal, N. Al-Ansari, and M. Naushad (2020). Waste Foundry Sand/MgFe-Layered Double Hydroxides Composite Material for Efficient Removal of Congo Red Dye from Aqueous Solution. Scientific Reports, 10(1); 1-12

Alam, M. A. and K. Al Riyami (2018). Shear Strengthening of Reinforced Concrete Beam using Natural Fibre Reinforced Polymer Laminates. Construction and Building Materials, 162; 683-696

Albo, J., M. I. Qadir, M. Samperi, J. A. Fernandes, I. de Pedro, and J. Dupont (2021). Use of an Optofluidic Microreactor and $\mathrm{Cu}$ Nanoparticles Synthesized in Ionic Liquid and Embedded in $\mathrm{TiO}_{2}$ for an Efficient Photoreduction of $\mathrm{CO}_{2}$ to Methanol. Chemical Engineering Journal, 404; 126643

Ali, F., N. Ali, I. Bibi, A. Said, S. Nawaz, Z. Ali, S. M. Salman, H. M. Iqbal, and M. Bilal (2020). Adsorption Isotherm, Kinetics and Thermodynamic of Acid Blue and Basic Blue Dyes onto Activated Charcoal. Case Studies in Chemical and Environmental Engineering, 2(9); 100040 
Biesinger, M. C., B. P. Payne, A. P. Grosvenor, L. W. Lau, A. R. Gerson, and R. S. C. Smart (2011). Resolving Surface Chemical States in XPS Analysis of First Row Transition Metals, Oxides and Hydroxides: $\mathrm{Cr}, \mathrm{Mn}, \mathrm{Fe}, \mathrm{Co}$ and $\mathrm{Ni}$. Applied Surface Science, 257(7); 2717-2730

Brame, J. A. and C. S. Griggs (2016). Surface Area Analysis using The Brunauer-Emmett-Teller (BET) Method: Scientific Operation Procedure Series: SOP-C. U.S Army Engineer Research and Development Center, 1; 1-23.

Chang, C. C. and R. Li (2019). Agricultural Waste. Water Environment Research, 91(10); 1150-1167

Chen, X., Q. Lin, R. He, X. Zhao, and G. Li (2017). Hydrochar Production from Watermelon Peel by Hydrothermal Carbonization. Bioresource Technology, 241; 236-243

Cheng, Z.L., Y. X. Li, and Z. Liu (2018). Study on Adsorption of Rhodamine $\mathrm{B}$ onto Beta Zeolites by Tuning $\mathrm{SiO}_{2} / \mathrm{Al}_{2} \mathrm{O}_{3}$ ratio. Ecotoxicology and Environmental Safety, 148; 585-592

Dang, W., J. Zhang, H. Nie, F. Wang, X. Tang, N. Wu, Q. Chen, X. Wei, and R. Wang (2020). Isotherms, Thermodynamics and Kinetics of Methane-Shale Adsorption Pair Under Supercritical Condition: Implications for Understanding The Nature of Shale Gas Adsorption Process. Chemical Engineering Journal, 383; 123191

Fan, X., Deng, L., Li, K., Lu, H., Wang, R., and Li, W (2021). Adsorption of Malachite Green in Aqueous Solution using Sugarcane Bagasse-Barium Carbonate Composite Colloids and Interface Science Communications, 44; 100485

Grabi, H., F. Derridj, W. Lemlikchi, and E. Guénin (2021). Studies of The Potential of a Native Natural Biosorbent for The Elimination of An Anionic Textile Dye Cibacron Blue in Aqueous Solution. Scientific Reports, 11(1); 1-13

Ikhtiari, R., H. Aziz, R. Zein, et al. (2015). The Removal of $\mathrm{Cr}(\mathrm{VI})$ with Dimocarpus longan as a Low Cost Biosorbent. Journal of Chemical and Pharmaceutical Research, 7(9S); 81-88

Ismail, S. N. A. S., W. A. Rahman, N. A. A. Rahim, N. D. Masdar, and M. L. Kamal (2018). Adsorption of Malachite Green dye From Aqueous Solution using Corncob. In AIP Conference Proceedings, 2031; 020036

Juleanti, N., N. R. Palapa, T. Taher, N. Hidayati, B. I. Putri, and A. Lesbani (2021). The Capability of Biochar-Based $\mathrm{CaAl}$ and $\mathrm{MgAl}$ Composite Materials as Adsorbent for Removal Cr (VI) in Aqueous Solution. Science and Technology Indonesia, 6(3); 196-203

Kalak, T., J. Walczak, and M. Ulewicz (2021). Adsorptive Recovery of Cd (II) Ions with The Use of Post-Production Waste Generated in the Brewing Industry. Energies, 14(17); 5543

Karthikeyan, P. and S. Meenakshi (2020). Enhanced Removal of Phosphate and Nitrate Ions by a Novel ZnFe LDHsActivated Carbon Composite. Sustainable Materials and Technologies, 25; e00154

Kaykhaii, M., M. Sasani, and S. Marghzari (2018). Removal of Dyes from The Environment by Adsorption Process. Chemical and Materials Engineering, 6(2); 31-35

Krishni, R., K. Foo, and B. Hameed (2014). Food Cannery
Effluent, Pineapple Peel as an Efective Low-Cost Biosorbent for Removing Cationic Dye from Aqueous Solutions. Desalination and Water Treatment, 52(31-33); 6096-6103

Kumari, S., A. A. Khan, A. Chowdhury, A. K. Bhakta, Z. Mekhalif, and S. Hussain (2020). Efficient and Highly Selective Adsorption of Cationic Dyes and Removal of Ciprofloxacin Antibiotic by Surface Modified Nickel Sulfide Nanomaterials: Kinetics, Isotherm and Adsorption Mechanism. Colloids and Surfaces A: Physicochemical and Engineering Aspects, 586; 124264

Kurniawati, D., T. Sari, F. Adella, S. Sy, et al. (2021). Effect of Contact Time Adsorption of Rhodamine B, Methyl Orange and Methylene Blue Colours on Langsat Shell with Batch Methods. In Journal of Physics: Conference Series, 1788; 012008

Kurniawaty, D. (2019). Effect of Cadmium in Biosorption of Lead by Lengkeng Seed and Shell (Euphoria logan lour). Journal of Chemical Natural Resources, 1(2); 23-29

Kusrini, E., Kinastiti, D. D., Wilson, L.D., Usman, A., Rahman, A (2019). Adsorption of Lanthanide Ions from an Aqueous Solution in Multicomponent Systems using Activated Carbon from Banana Peels (Musa Paradisiaca L.). Journal of Chemical Natural Resources, 19; 1132-1139

Lesbani, A., N. R. Palapa, R. J. Sayeri, T. Taher, and N. Hidayati (2021). High Reusability of NiAl LDH/Biochar Composite in the Removal Methylene Blue from Aqueous Solution. Indonesian Journal of Chemistry, 21(2); 421-434

Lestari, N. A. (2019). Reduction of $\mathrm{CO}_{2}$ Emission by Integrated Biomass Gasification-Solid Oxide Fuel Cell Combined with Heat Recovery and in-situ $\mathrm{CO}_{2}$ Utilization. Evergreen, 6(3); 254-261

Ma, J., L. Hou, P. Li, S. Zhang, and X. Zheng (2021). Modified Fruit Pericarp as an Effective Biosorbent for Removing Azo Dye from Aqueous Solution: Study of Adsorption Properties and Mechanisms. Environmental Engineering Research, 27(2); 200634

Mamat, M., M. A. A. Abdullah, M. A. Kadir, A. M. Jaafar, and E. Kusrini (2018). Preparation of Layered Double Hydroxides with Different Divalent Metals for The Adsorption of Methyl Orange Dye from Aqueous Solutions. Chemical Engineering, 9(6); 1103-1111

Mishra, S., S. Sahoo, A. Debnath, K. Muthe, N. Das, and P. Parhi (2020). Cobalt Ferrite Nanoparticles Prepared by Microwave Hydrothermal Synthesis and Adsorption Efficiency for Organic Dyes: Isotherms, Thermodynamics and Kinetic Studies. Advanced Powder Technology, 31(11); 45524562

Moghadam, M. R., N. Nasirizadeh, Z. Dashti, and E. Babanezhad (2013). Removal of Fe(II) from Aqueous Solution using Pomegranate Peel Carbon: Equilibrium and Kinetic Studies. International Journal of Industrial Chemistry, 4(1); $1-6$

Moller, M., and Pich, A (2017). Development of Modified Layered Silicates with Superior Adsorption Properties for Uptake of Pollutants from Air and Water. Development of 
Modified Layered Silicates with Superior Adsorption Properties for Uptake of Pollutants from Air and Water Von. Disertation; University Zur Erlangung Des

Moosa, A., Ridha, A., Moosa, A.A., Ridha, A.M., Hussien, N.A (2016). Removal of Zinc Ions from Aqueous Solution by Bioadsorbents and CNTs Removal of Zinc Ions from Aqueous Solution by Bioadsorbents and CNTs. International Journal of Industrial Chemistry, 5; 1-10

Neolaka, Y. A., Y. Lawa, J. N. Naat, A. A. Riwu, M. Iqbal, H. Darmokoesoemo, and H. S. Kusuma (2020). The Adsorption of $\mathrm{Cr}(\mathrm{VI})$ from Water Samples using Graphene Oxide-Magnetic $\left(\mathrm{GO}-\mathrm{Fe}_{3} \mathrm{O}_{4}\right)$ Synthesized from Natural Cellulose-Based Graphite (Kusambi Wood or Schleichera oleosa): Study of Kinetics, Isotherms and Thermodynamics. Journal of Materials Research and Technology, 9(3); 65446556

Nor, N. M., T. Hadibarata, Z. Yusop, and Z. M. Lazim (2015). Removal of Brilliant Green and Procionred Dyes from Aqueous Solution by Adsorption using Selected Agricultural Wastes. Jurnal Teknologi, 74(11); 117-122

Normah, N., N. Juleanti, P. M. S. B. N. Siregar, A. Wijaya, N. R. Palapa, T. Taher, and A. Lesbani (2021). Size Selectivity of Anionic and Cationic Dyes Using LDH Modified Adsorbent with Low-Cost Rambutan Peel to Hydrochar. Bulletin of Chemical Reaction Engineering \& Catalysis, 16(4); 869-880

Oliveira, E., J. Santos, A. Goncalves, S. Mattedi, and N. Jose (2016). Characterization of The Rambutan Peel Fiber (Nephelium lappaceum) as a Lignocellulosic Material for Technological Applications. Chemical Engineering Transactions, 50; 391-396

Onder, A., P. Ilgin, H. Ozay, and O. Ozay (2020). Removal of Dye from Aqueous Medium with pH-Sensitive Poly [(2(acryloyloxy) ethyl] Trimethylammonium Chloride-co-1vinyl-2-pyrrolidone] Cationic Hydrogel. Journal of Environmental Chemical Engineering, 8(5); 104436

Pathak, P.D., Mandavgane, S.A., Kulkarni, B.D. (2015). Fruit Peel Waste as a Novel Low-Cost Biodsorbent. Revieres in Chemical Engineering, 31; 361-381

Priyanto, A., F, M., Muhdarina, M., A, A.(2021). Adsorption and Characterization of Activated Sugarcane Bagasse Using Natrium Hydroxide Indonesian Journal Chemical Research, 8; 202-209

Qu, W., T. Yuan, G. Yin, S. Xu, Q. Zhang, and H. Su (2019). Effect of Properties of Activated Carbon on Malachite Green Adsorption. Fuel, 249; 45-53

Rahmanian, O., M. Dinari, and M. K. Abdolmaleki (2018). Carbon Quantum Dots/Layered Double Hydroxide Hybrid for Fast and Efficient Decontamination of Cd (II): The Adsorption Kinetics and Isotherms. Applied Surface Science, 428; 272-279

Satya, A., Harimawan, A., Haryani, G. S., Johir, M. A. H., Vigneswaran, S., Ngo, H. H., Setiadi, T (2020). Batch Study of
Cadmium Biosorption by Carbon Dioxide Enriched Aphanothece sp. Dried Biomass. Water, 12; 1-10

Shaikhiev, I. G., N. V. Kraysman, and S. V. Sverguzova (2022). Onion (Allium Cepa) Processing Waste as a Sorption Material for Removing Pollutants from Aqueous Media. Biointerface Research in Applied Chemistry, 12(3); 3173-3185

Tariq, M., M. Muhammad, J. Khan, A. Raziq, M. K. Uddin, A. Niaz, S. S. Ahmed, and A. Rahim (2020). Removal of Rhodamine B dye from Aqueous Solutions using PhotoFenton Processes and Novel Ni-Cu@ MWCNTs Photocatalyst. Journal of Molecular Liquids, 312; 113399

Ting, A. S. Y., C. K. W. Cheng, and K. A. A. Santiago (2021). Decolourization of Malachite Green Dye by Endolichenic Fungi from The Lichen Usnea sp. : A Novel Study on Their Dye Removal Potential. Journal of King Saud University Science, 33(7); 101579

Tongpoothorn, W., O. Somsimee, T. Somboon, and M. Sriuttha (2019). An Alternative and Cost-Effective Biosorbent Derived from Napier Grass Stem for Malachite Green Removal. Journal of Materials and Environmental Sciences, 10(8); 685-695

Vasu, A. E. (2007). Biosorption of Rhodamine B and Malachite Green from Aqueous Aolutions by Tamarindus Indica Fruit Shells. Current World Environment, 2(2); 127

Wang, L., A. Li, and Y. Chang (2016a). Hydrothermal Treatment Coupled with Mechanical Expression at Increased Temperature for Excess Sludge Dewatering: Heavy Metals, Volatile Organic Compounds and Combustion Characteristics of Hydrochar. Chemical Engineering Journal, 297; $1-10$

Wang, Y., L. Zhu, H. Jiang, F. Hu, and X. Shen (2016b). Application of Longan Shell as Non-Conventional Low-Cost Adsorbent for The Removal of Cationic Dye from Aqueous Solution. Spectrochimica Acta Part A: Molecular and Biomolecular Spectroscopy, 159; 254-261

Wijaya, A., P. M. S. B. N. Siregar, A. Priambodo, N. R. Palapa, T. Taher, and A. Lesbani (2021). Innovative Modified of $\mathrm{Cu}-\mathrm{Al} / \mathrm{C}(\mathrm{C}=$ Biochar, Graphite) Composites for Removal of Procion Red from Aqueous Solution. Science and Technology Indonesia, 6(4); 228-234

Yonika, K. D. . K. M., S. (2021). Adsorption of Rhodamin-B Dyes using Active Carbon of Longan Shell (Euphoria Longan lour) with Batch Method. International Journal of Scientific Research and Engineering Development, 4(5); 239-243

Zhang, J., M. Liu, T. Yang, K. Yang, and H. Wang (2016). A Novel Magnetic Biochar from Sewage Sludge: Synthesis and Its Application for The Removal of Malachite Green from Wastewater. Water Science and Technology, 74(8); 1971-1979

Zubair, M., N. Jarrah, A. Khalid, M. S. Manzar, T. S. Kazeem, M. A. Al-Harthi (2018). Starch-NiFe-Layered Double Hydroxide Composites: Efficient Removal of Methyl Orange from Aqueous Phase. Journal of Molecular Liquids, 249; $254-$ 264 